\title{
You Are Here: Pain and its Location
}

[Você Está Aqui: Dor e sua Localização]

\author{
Simone Gozzand
}

\begin{abstract}
When we consider bodily pain, it seems we are uniquely in the realm of the first person only, with no space for a second person. In this paper, I shall argue that it is in the interplay between the first and second persons, the social dimension of language, that our use of locative spatial terms inherits its rules and constraints. This interplay, in a form of triangulation proposed by Davidson, could provide us with a viable solution to the problem of the location of bodily pain. The solution lies in adopting representationalism while recognizing the limits of the representational system.
\end{abstract}

Keywords : Pain. Location of Pain. Representationalism. Experientialism. Triangulation. Second Person.

Resumo: Quando consideramos a dor corporal, parece que estamos exclusivamente no reino da primeira pessoa, sem espaço para uma segunda pessoa. Neste artigo, argumentarei que é da interação entre a primeira e a segunda pessoas, a dimensão social da linguagem, que nosso uso de termos espaciais locativos herda suas regras e restrições. Essa interação, em uma forma de triangulação proposta por Davidson, poderia nos fornecer uma solução viável para o problema da localização da dor corporal. A solução está em adotar o representacionalismo enquanto se reconhece os limites do sistema representacional.

Palavras-chave: Dor. Localização da Dor. Representacionalismo. Experiencialismo. Triangulação. Segunda Pessoa.

${ }^{\star}$ Full Professor at the Department of Human Studies of the University of L'Aquila (Italy). E-mail: simone.gozzano@univaq.it. ORCID: https://orcid.org/ 0000-0002-2956-4120. 
The problem of the location of bodily pain still baffles philosophers. Two main theories have developed largely in opposition to each other. One claims that feeling pain entails representing a damaged body part as painful. The other, that feeling pain entails a mental experience and the location of pain is purely experiential: pain is located in the mind, not in the body. In this paper, which explores what establishes the content of our mental states of bodily pain, I will use the davidsonian concept of triangulation to address the problem of locating pain. I contend that by considering the crucial role triangulation plays in determining both public and intersubjective language use, we can defend the view that it is consistent and reasonable to represent pain as something that also happens in the body, and that the concept of second person plays a pivotal role in such a representation.

I will proceed as follows. First, I show why the issue of pain location is problematic, by describing the two main theoretical contenders: representationalism and experientialism. Then, I briefly outline Davidson's concept of triangulation and how he establishes the importance of the second person. Finally, I will try to show how, by adopting Davidson's conceptual framework, we can move towards a solution to the problem of the location of bodily pain.
In particular, I argue that to make sense of the second person perspective, we need to assume that pain reports are on a par with perceptual reports and that the challenges to this view relate to the limits of our representational system rather than any failings in representational theory itself.

\section{Representationalism vs experienti- alism}

Murat Aydede (2019), in a very effective paper, asks: is pain the perception of something or is it rather a form of introspection? Two main theories address this question which probes the location of pain: representationalism and experientialism. Most scholars (Aydede 2009; Bain 2003, 2007; Cutter 2017; Tye 1995, 2014, 2017) either adhere to or challenge one these two theories, which differ in locating pain but are otherwise somehow similar. Yet, they are not the only two theories in town (cfr. Klein 2015).

According to representationalism (also known as perceptualism/representationalism, henceforth $P / R)$, when we utter: "I feel pain in my toe" we are engaging "in a form of sense perception" [1] which establishes a relationship between our awareness and some disturbed or damaged body part. This type of perceptual relation deter-

\footnotetext{
${ }^{1}$ Pitcher (1970: 368).
} 
mines a representation, whose content is that a certain body part is disturbed, and that this disturbance is bad for us as subjects..$^{2}$ Michael Tye, for one, has argued that the representational content of a pain experience is the phenomenal character of this experience itself. So, the phenomenal differences brought about by the damage leads to different representational contents, that also specify where the pain is represented to be. $?^{3}$

In its more radical version, the $P / R$ view takes the perceptual relation in more literal terms. David Bain has argued that in feeling pain a subject somatosensorily perceives a body part "from within" as having a property or undergoing some process - that consists in having a disorder or a disturbance..$^{4}$ In analogy with representationalism, the content of the phenomenal character of this somatosensory experience is fixed by the experience itself, i.e., it is determined by what is represented to be the case. Thus, the location is part of the representation itself: "The difference between the subject having a pain in one location and in another partly consists in - or, alternatively, constitutes - a difference in the phenomenal character of the experience $S$ undergoes between the two cases". 5 Consequently, different locations entail different experiences.

We may say that the truth-condition for John's saying "I feel pain in my toe" is that he has a

[...] subjective experience that (non-conceptually or in ana$\log$ format) represents his toe as having a physical disorder of the appropriate kind in it. This experience is veridical if John's toe has indeed such a disorder (and is relevantly caused by the disorder) - nonveridical otherwise. So, if John's pain in his toe is caused by a nerve compression in his lower back, then John's subjective experience is inaccurate, nonveridical." (Aydede 2019: 7)

So, representationalists recognize that pains are subjective experiences, but they take these to be intentional states attributing physical disorders to body parts. As we have seen, according to representationalists, different locations entail different experiences. Herein lies a potential difficulty. The contrapositive of this claim, that same experiences entail same locations, has the following consequence: suppose that

\footnotetext{
${ }^{2}$ A number of authors are now discussing whether pain is intrinsically bad. See Cutter and Tye (2011), Bain (2013), and the essays in Corns (2017).

${ }^{3}$ See, in particular, Tye (1995, 2006a, 2006b, 2016, 2017), Cutter (2017) and Dretske (2006).

${ }^{4}$ Bain (2007: 175) but see also Bain (2003).

${ }^{5}$ Bain (2007: 177).
} 
hallucinating a pain in a missing toe has the same experiential phenomenology as feeling a pain in an actual toe. If this were the case, the two experiences would be true of the same location. Evidently, however, one location is missing. So, to maintain the entailment, the supposedly same location cannot be a physical body part. Hence, it must be a representational body part. The fact is that the same experience may, in one case, be the result of a perceptual relation to a bodily part and, in another case, be the result of a representational relation to a represented body part. How can representations keep track of these different relata?

The way out proposed by some representationalists has been to stress that the object of pain perception is not the body part, but rather the perceptual representation we have of that body part: "We say that we have a pain in the hand. The sensation of pain can hardly be in the hand, for sensations are in minds and the hand is not part of the mind". 6 Therefore: "the 'location' of pain is [...] an intentional location".7 This comes pretty close to a second theory.

The second theory, mainly defended by Murat Aydede (2005; 2009; 2013; 2017) among others, does not allow experiences of pain to be conceived as relational representations. Rather, the idea is that:

There is a pain quale instantiated in the experience which presents John's toe to John in a certain way: this is a way John's toe appears to John without making any claim on the condition of his toe. John may come to believe or judge that something is (physically) wrong with his toe as expected. But this is not a proper perceptual judgment directly based on the pain experience - it's inferential but usually quite habitual. (Aydede 2020: 154).

So, the contents of our experiences are divorced from the physical conditions of the body location to which such contents are projected, making representationalism's way out of the dilemma insufficient. If experiential contents are adverbial, that is, they modify the whole experience of the subject, and thus are not relational, they do not connect experiences with anything external to them. The main reason to defend the experientialist view lies in acknowledging that pain reports express what the

\footnotetext{
${ }^{6}$ Armstrong and Malcolm (1984: 182).

${ }^{7}$ Armstrong (1968: 315). Armstrong distinguishes between transitive vs. intransitive sensations. A sensation is transitive if its quality exists independently of the existence of minds, intransitive if it is mind dependent. While pain prima facie appears to be intransitive, actually it is transitive. In order to make this transitivity evident, Armstrong argues that pain reports have this hidden form: "It feels to me that certain sort of disturbance is occurring in my hand, a perception that evokes in me the peremptory desire that the perception should cease" Armstrong (1968: 314).
} 
subject is feeling, not what is happening to the body of the subject. Imagine hallucinating a pain in the toe and reporting that you feel pain in the toe. The report is as accurate as it can be because hallucinating a pain is feeling a pain, no matter what is happening to the toe. One example of hallucinating pain could be the case of phantom pain, in which people feel pain in a limb that has been surgically removed. If a report of phantom pain is expressed, one cannot deny that the subject is suffering. In this case, the experientialist seems to be in a better position than is the $\mathrm{P} / \mathrm{R}$ theorist, because the latter has to explain why the subject is "wrong" in representing the pain in a missing bodily location while the former does not need any supplemental explanation for the case: it is the experience that matters. It is important, then, to better understand the logic behind these different theories.

\section{The supposed independence of sen- sations and damages.}

The definition of pain provided by The International Association for the Study of Pain - IASP (Raja 2020) goes as follows: "An unpleasant sensory and emotional experience associated with, or resembling that associated with, actual or potential tissue damage". 8 As a side note, it is also stressed that "Through their life experiences, individuals learn the concept of pain". The very definition underlines that the experienced association could be with either actual or potential tissue damages, thus allowing for the absence of any actual damage. As a matter of fact, the relation between the sensation and the damage is complex. There are at least three cases in which this complexity surfaces: referred, chronic and phantom pain.

A pain is called "referred" when pain is felt at a site remote from the site of origin/stimulation (Arendt-Nielsen 2001). For instance, this occurs if a nerve in the spine is pinched or stimulated and pain is felt in the leg or in the case of pain felt in the arm during a heart attack. We lack a common definition for referred pain since the IASP has not yet provided one.

A pain is chronic when an original acute pain event, whose immediate cause has subsequently been removed, continues to distress the subject. Basically, the subject still feels pain in an area or spot even if nothing is wrong in that area or spot any longer (chronic back pain is a typical example). Finally, pain in a phantom limb, which could be seen as a variety of chronic pain, occurs when people who have undergone surgical amputation of a limb continue

\footnotetext{
${ }^{8}$ The previous definition was "An unpleasant sensory and emotional experience associated with actual or potential tissue damage or described in terms of such damage" and was released in 1986. After a long review process, which also included counseling from philosophers, the new definition was released.
} 
to feel pain in the regione previously occupied by the removed limb. The pain is attributed to a location adjacent to the stump, where the missing limb would still be if it had not been removed. 9

All these cases can be marshalled against the $P / R$ analysis inasmuch as representationalism strongly relates the sensation to its physical origins. However, it is possible to feel pain when nothing is wrong in the physical location where the pain is represented to be. Christopher Hill $(2004,2006)$ describes different views on the location of pain by stressing that the $P / R$ view takes pain to be located where we represent it to be, while the experiential view takes our feelings of pain to be endowed with a location.10 The first view considers the location of pain de re, a perceptual object external to the representation; the experiential view takes location de dicto, since the location is a constituent of the content of the experience.

This difference is at the core of Aydede's initial argument against perceptual views on pain: veridical perceptual reports (thus excluding hallucinations and illusions) allow for existential exportation, an inference that leads from a true statement of the form "I perceive $x$ " to a statement of the form "there is an $x$ such that I perceive it". This is not the case in pain reports. In such cases, from a veridical statement of the form "I feel pain in $x$ " we cannot infer "there is an $x$ such that I feel pain in it", as the case of phantom pain makes clear. Moreover, it should be noticed that in the case of hallucination or illusion, only perceptual not introspective reports become false. ${ }^{11}$ The reason for this, Aydede argues, is because the concept of pain is applied "only to express or specify the representational content of paine [pain as experience]"12 and this occurs because we are not interested in using the concept of pain to label the damages, but rather to point to the experience itself. As Kripke (1980) pointed out, when it comes to pain the distinction between appearance and reality vanishes: what seems to be pain simply is pain, so it is experience that matters, not its physical origin or cause.

According to Aydede, representationalism is untenable because it has to consider the experiences determined by phantom, referred and chronic pains as inaccurate or non-veridical because they are inaccurate or false with respect to the physical or location of pain. However, the experientialist argues that such reports perfectly describe the

\footnotetext{
${ }^{9}$ Clearly, I cannot enter into the clinical details of these brief descriptions. For instance, I do not say anything about why a given acute pain event becomes chronic pain.

${ }^{10}$ See Hill (2017).

${ }^{11}$ For a different evaluation of illusion in pain see Reuters, Philips and Sytsma (2013).

${ }^{12}$ Aydede (2009: 549).
} 
experience and so, from that point of view, must be true. It would seem preposterous to tell suffering subjects that their experiences are non-veridical. An affirmation of non-veridicality results only from a representationalist view, not from the subject's experience. If this view is abandoned, the inaccuracy disappears.

So, it is erroneous to contrast the subjective experience of pain with an objective location of damage that presumably, or in most cases, causes that experience. According to Aydede, the situation is not improved if we take the quality to be a naturalistic quality or a self-representing quality. In both cases the accuracy conditions are found faulty. So, the representationalist model should be abandoned. But is the experientialist view any better? Here we need to consider Davidson's triangulation and the externalist view on meaning.

\section{Experientialism and triangulation}

According to experientialism, perceptual reports and pain reports have different truth-conditions: the former have their truth-conditions in the world, the latter in the mental states of subjects. Perceptual reports allow for existential exportation while pain reports do not. However, I think this difference deter- mines the problem, rather than the solution. The problem is an implicit denial of content externalism, which I believe we have good reasons to endorse. Without rehearsing arguments for content externalism here ${ }^{13}$, one of these reasons is simply to avoid any kind of scepticism - such as that presented by Wittgenstein - regarding the intelligibility of mental contents, an intelligibility on which both sides seem to agree. The fact is that experientialism poses a divide between the first and second person, the experiencer and the observer, so to say. And such a divide prevents, or makes it very difficult, to consider meaningful interactions with respect to the case of pain. Let me further articulate this by quickly presenting Davidson's view on the issue.

Within the framework of a social theory of meaning and language, Davidson points to the crucial role of a mechanism he calls "triangulation", a process consisting of "the mutual and simultaneous responses of two or more creatures to common distal stimuli and to one another's responses" (Davidson 2001: xv). Triangulating provides an objective measure of our empirical contents, that is, the content of our epistemic states relative to external world. Davidson captures the gist of such a method: "It is the result of a threefold interaction, an interaction which is twofold from the point of view of

\footnotetext{
${ }^{13}$ Arguments such as those set forth by Putnam, Kripke and Burge, to mention only the "founding fathers" of externalism.
} 
each of the two agents: each is interacting simultaneously with the world and with the other agent. To put this in a slightly different way, each creature learns to correlate the reactions of other creatures with changes or objects in the world to which it also reacts." (1997: 128). Such happenings and objects are interpreted by Davidson in pre-intentional, pre-cognitive and prelinguistic terms because triangulation is a precondition for the development of full-blown thoughts. So, triangulation is something that also happens among non-speaking creatures, such as infants and animals.

The interaction with the world determined by triangulation is a causal one: we know what another creature is reacting to because we are able to triangulate with that creature and with the source of its reactions. So, the edges of the "triangle" are not strictly speaking uniform: the two edges that go from the common worldly origin to the creatures are causal, the one that connects the two creatures to each other are interpretative, even if in a very vague and wide sense. To use a davidsonian category, this last edge is the one that vehiculates reasons (even if we still are in a pre-linguistic/cognitive/intentional domain). 14 The causal edge that connects each individual with the mundane origin of its mental state is of paramount importance because, as Davidson himself states: "since it is, in the simplest cases, what causes a belief that gives it its content" (1997: 129). While Davidson is here speaking of belief ${ }^{15}$, we could refer to the content of our experiences: the cause of an experience of pain is the one that gives that experience its content. Not all notions of triangulation would do, though. Two possible readings are available: the basic one, where neither subject in the interaction masters concepts, and a more evolved one, in which both subjects have mastered concepts and have a fullfledged language. (Davidson 1998a) ${ }^{16}$ I wish to consider the first variety of triangulation. In the first case, triangulation allows us to identify what can be considered as the "typical" cause of empirical content.

One problematic issue, at this point, is the origin of the cause. In order for this origin to be one on which two or more subjects may refer, it has to be external to all subjects. So, it seems, the source cannot be on the skin or,

\footnotetext{
${ }^{14}$ This is the reason why Davidson thinks that triangulation is a necessary but not sufficient basis for having thoughts: language is what is needed, and it is language that ensures the 'base line' - as the edge that connects the two subjects is sometimes called - is effective.

${ }^{15}$ As many scholars have pointed out (see the discussion in Amoretti 2012), Davidson's strategy cannot constitute the basis for thought if we have to consider the second person as one endowed with language since, as Davidson himself claims, thought and language are interdependent. However, this problem, which is a serious one (see Gozzano 1997), should not worry us because it is beyond our present concerns and because we are adopting the triangulation method as a way to make sense of the referent of the source of bodily pain, which is experiential and so pre-intentional, pre- cognitive and pre-linguistic.

${ }^{16}$ For a third form of triangulation, one in which only one of the interpreters masters a language, see Amoretti (2013: 53).
} 
worse, below the skin of one of the subjects, because such a cause would be unavailable to the second subject, thereby ruling out triangulation from the very beginning. But we should not remain trapped in the "myth of the subjective". As Davidson himself stresses, we can admit a social and objective concept of truth, while accepting that thoughts and, I would add, experiences, are subjective. Here is how he makes this point:

[... two features of the subjective as classically conceived remain in place. Thoughts are private, in the obvious but important sense in which property can be private, that is, belong to one person. And knowledge of thoughts is asymmetrical, in that the person who has a thought generally knows he has it in a way in which others cannot. But this is all there is to the subjective. So far from constituting a preserve so insulated that it is a problem how it can yield knowledge of an outside world, or be known to others, thought is necessarily part of a common public world. Not only can others often learn what we think by noting the causal dependencies that give our thoughts their content, but the very possibility of thought demands shared standards of truth and objectivity. (Davidson 1998b: 52)

Clearly, experiential contents are private and have privileged (asymmetrical) access. So, they are definitively in the realm of the subjective. But they are also fixed through causal relations, and these can be taken to sustain truth and objectivity. Let me explain in what sense this is so.

In expressing the content of our experiences, for instance, in pain reports that attribute qualitative features to bodily locations, it is essential for the terms used to be as semantically valuable as any other term. The intelligibility of words, such as "pain, annoyance, nuisance", used in pain reports is found in the same structure of reference and predication that holds for any other word. It is by triangulating that we enjoy a stable, shared context for understanding the content of pain reports. The importance of this method cannot be underestimated since it is in the context of interactions that we learn the words for pain.

As the IASP's definition of pain stresses, we learn words for pain through interactions with our caregivers when we first experience bodily damage. Here, interaction is the key element. We learn the concept of pain by interacting with others with respect to our own bodily condition. When these interactions are no longer needed or available, we interact with ourselves, in particular with 
the messages coming from our body. And it is exactly here that we encounter the limited reliability of our bodily signals. ${ }^{17}$

The point can be described through the process of triangulation itself. Imagine two people: John, who is wounded, and Jill, who is not. Jill points toward John's wound and say, "That must be painful". John points to his own wound and says: "That is painful". Now, the truth conditions of John's sentence are rooted in the experience he his having. As Aydede says "the truth conditions of [pain report] put no constraints whatsoever on how things physically are with [body part]" (Aydede 2009: 533). What about those of Jill? Either Jill is referring to John's experience or she is referring to the cause of his experience by putting herself in John's shoes. If she is referring to John's experience - we could read her sentence as "you must be having a painful experience" - then her sentence has different truth conditions from John's because it allows for existential exportation: there is something, a painful experience, that John is having whose manifestations Jill is perceiving. If, on the other hand, she is referring to the cause of John's experience - if we are to read her as saying "that [wound] must be causing a painful experience to you" - then, again, the truth condition of her expression is different since the wound constitutes a perceptual content, which allows for existential exportation. In both cases, then, the content of Jill's report allows for exportation. Consequently, given the difference of their truth conditions, their willingness to refer to the very same spot fails, notwithstanding their apparently successful communicative coordination. For, John points to a location which is captured in de dicto mode, while Jill points to it in de re mode and the two are logically and categorically distinguished. Notice, the difference in the truth conditions is not to be found in some sort of semantic or perceptual path - like those imagined by Kripke (1979) in Pierre's puzzle. The difference, as we saw, is in the structure of reference, in its logic, as stressed in Aydede's initial argument. In referring to the location of John's painful wound, both John and Jill are deluded with respect to the efficacy of their communication: any possible pragmatic success is just an illusion. ${ }^{18}$

This problem also presents itself in the case of a person who perceives damage to her body and at the same time experiences pain. While a bruise on the skin is a perceptual object, for which existential exportation is acceptable, the pain that one feels in the (apparently) same location is not. For, if I see a bruise on my leg, there is a bruise I

\footnotetext{
${ }^{17}$ On the communicative role of self-talk, see Deamer (2021).

${ }^{18} \mathrm{An}$ analysis of the logic and grammar of pain reports is in Brogaard $(2011,2012)$.
} 
am seeing, but if I feel pain in the same spot where that bruise is, I cannot export that spot as one that is painful. So, the two locations only apparently coincide spatially (cfr. Gozzano 2019).

Abandoning triangulation, and externalism, for the content of our experiences would force us to abandon a very plausible reading of how language roots the concepts used in experiential reports in the public space. Without this "rootedness", we cannot make sense of our articulated responses to pains, which help us better understand what is happening to our fellow beings. Such triangulation, as Davidson states, is necessary to get what concepts a person is using and having. Davidson makes this clear by noting how we attribute reactions to an animal. The case is relevant to my point. Because animals cannot speak and it is doubtful that they have thoughts (at least, Davidson strongly denies they have any thoughts), their situation is comparable to one in which a person has experiences which we cannot directly access because we are attributing hypothetical experiences from their perceptual manifestations. Davidson says: "In the case of the dog, why say the stimulus is the ringing of the bell? Why couldn't it be the vibration of the air close to the ears of the dog-or even the stimulation of its nerve endings? ... What explains the fact that it seems so natural to say the dog is responding to the bell ...? It seems natural to us because it is natural-to us" (1992, 262). Assuming stimuli are those that seem natural to us also paves the road to our understanding what is happening when someone feels pain: concepts that are natural-tous must be natural to everyone if we are to exchange reports on internal goingson, even those to which we do not have any direct access.

These considerations are relevant to the problem of pain because we are guided by such criteria in determining the truth-makers of our experiential contents. We feel pain and we are informed that people are in pain more or less in the same way that the body informs us that we are in pain. The content of the sensation [pain in the toe] is conveyed to us directly and we convey this to other people indirectly, but we use the same contents (or, at least, strive to do so). So, there is some content preservation here, even if we have to transcode this content from a proprioceptive to a linguistic mode.

Experientialism, vice versa, loses any trace of "objectivity" in the concept of pain. To make sense of such objectivity, Davidson argues that we must accept that the world and our experiences may diverge. He thinks this can be attained by surprise: it is only if I can be surprised that I distinguish between my thoughts and the world. Can we be surprised in the case of pain? I think we can. Consider the experience of apparently uncaused tickles or unfelt bodily damage (cfr. Reuter and Sytsma 
2020). We are surprised by the noncoincidence of our experiential content and what we take to be their typical causes. Basically, as Verheggen (2007: 101) underlines: "Meanings are not somehow fixed by people who then in addition need the concept of objectivity in order to have a language. Rather, people need the concept of objectivity in order to fix meanings to begin with."

This gives us a clue to the way referred pain or chronic pain is handled, that is, to the conceptual ground for these diagnoses: it is by recognizing that it is surprising that the very same experience, back pain, occurs in people that feel pain because of the presence of a hernia and those that feel pain for a developed chronicity without any apparent physical origin. In both cases we fix the different origins of pain in conceptual and lexical terms: we call the one in the body "pain" without qualification and the one based on a cognitive or experiential habit "chronic pain", in order to objectively distinguish them despite their subjective similarity.

Given these criticisms of the experientialist view, is there a way to fix the $\mathrm{P} / \mathrm{R}$ model so as to overcome the difficulties outlined above? In the next section, I will argue that the objections to representationalism raised by Aydede result from potential malfunctioning of the representational system itself, a malfunctioning made apparent by the interactionist model which grounds the triangulation method proposed by Da- vidson. Moreover, such malfunctioning is part and parcel of our representational system, yielding an error theory for what happens when things "go wrong" in the case of phantom and referred pain, with a different twist in the case of chronic pain.

\section{Representationalism fixed: an error theory}

Supposedly, representationalism gets into trouble when cases such as phantom, chronic and referred pains are at stake. Because, in these cases, it cannot explain why subjects, at least apparently, systematically misrepresent the location where their pains originate or were caused. In order to avoid such a problem, experientialism moves, so to speak, all such locations into the experience of the subject. And this moving involves all the ordinary cases of pains, that is, those cases we are accustomed to and which have been the source of our learning and basic understanding of the concepts and words we use to describe painful sensations. Can we move these three difficult cases back into the body instead of moving the ordinary cases away from the body?

In one of his papers, Aydede (2020), developing a suggestion made by Austen Clark (2000), exploits an analogy with maps to explore the issue of location. Consider a map of some mountain area. The points on the map re- 
fer to points in reality, such as peaks or passes; the values associated with these points are depicted by colors or numbers that predicate something about these points. So, by depicting lines and specifying numbers, a map of a mountain can refer to a certain area of the landscape and predicate the properties of this area. The properties or components of the map, its symbolic features, should meet the requirements for language, in particular its publicness. That is to say, for example, each of us has to be able to determine which point represents the position and height of any peak. Analogously for passes, valleys, rivers and so forth. When we represent pain on our body, what is the structure of this representation and what representational system supports such a representation?

Consider John feeling pain in his toe. Prima facie, the content of John's experience is such that it refers to a body location, the toe, and predicates that it is the source of a painful sensation. The content of his experience helps him find the source of the pain just as the map helps one find one's way in the mountains. However, Aydede and the experientialists insist that:

Pain qualia are implemented by the proprietary predicates of the nociceptive system but are not representational in that they don't function to attribute any quality to the body parts presented in the same experience. Pain qualia are the phenomenally determinate ways in which our body parts are presented to us or appear to us. (Aydede 2020: 153).

So, we have experiences that instantiate qualia which do not attribute properties to people's body, but rather to the way in which bodies appear to people. Let me try to unpack this a little. In attributing qualities to body parts, qualia predicate the properties of the part to which they refer. These appearances, however, cannot refer to the body because they can be true even in the absence of damage, as per the "initial argument". They do not refer to the nociceptive system either because, if one were to endorse transitivity in causation and were to adopt a causal theory of reference, the quale refers to the signal coming from the nociceptive system, and this signal refers to the condition of the body, so ultimately the qualia would attribute the condition to the body, which runs counter to the initial argument. What is left, then? Basically, the qualia refer to themselves. John's qualia refer to the way that these qualia present John with the condition of John's own body. By virtue of their self-reflective reference and by predicating this self-reference, people cannot be mistaken with respect to the referential and predicative aspects of their qualia: such experiences vindicate 
Kripke's tenet that in case of pain and, presumably, other self-reflective inner states, appearance and reality coincide. But we are not forced to accept this conclusion. I propose that we stick with the representationalist solution instead.

The problem with representationalism, as we saw, is that it gives us the wrong answer in cases such as phantom, referred and chronic pain. However, I propose to use the map model as an error theory for representationalism. I will argue that the difficulties representationalism runs into are due to a failure of the representational system, that is to the way our cognitive system works and how it implements the body map, rather than to the metaphysics of representationalism itself.

Consider you are reading a floor map in a museum you are visiting. You will likely find a red dot labelled, "You are here".

It works like this:

(1) The map represents the museum floor.

(2) The dot represents you.

(3) The position of the dot on the map represents your position in the $\mathrm{mu}-$ seum.

(4) The position of the map [as a physical object] within the museum determines the correctness of the representational content of the map (3).

The representation of the museum floor plan has four possible degrees of freedom: the structure of the depicted floor, the condition of the dot, the position of the dot and, finally, the position of the maps $_{s}$, that is, as a sign hung on the wall. This last condition is fundamentally linked to the condition of external correctness, which is given by the position of the $\operatorname{map}_{s}$ in the space of the museum vis-a-vis the content of what is depicted on the $\operatorname{map}_{\mathrm{s}}$ itself. These four degrees of freedom allow for at least three possible mistakes. 1) The map is wrong or has not been updated with respect to the structure of the museum, that is, the map does not adequately represent the layout of the museum; 2) the dot has been worn away and you have to infer your positions from the worn away area, not from the presence of the original dot; 3 ) the position of the dot on the map is mistaken with respect to the position of the map $_{s}$ in the museum. We could also consider potential ambiguity: if the floor map is symmetrical, there are potentially dot positions which are ambiguous with respect to your position (for instance, in a circular room with two opposing doors: if the dot is midway between the two doors along the circumference, there is no way to tell which side of the room you are in.)

Suppose something like this occurs regarding the position of pain with respect to our body. The map is analogous to the body map, since it refers to the body as the depicted floor refers to the museum floor; the dot is the represen- 
ted source of the bodily pain; the position of the dot on the map is the representation of the pain location in or on the body. The position of the maps in the space (where it is hung) determines the correctness of its content and the correctness of the actions the subject takes with respect to this represented location: where she goes in the case of the museum, or where she looks for tissue damage in the case of bodily pain. ${ }^{19}$

The museum map analogy gives rise to three possible mistakes, which are the cases considered problematic for representationalism. To begin with, consider the case of pain in a phantom limb. Here, the representational system is mistaken about the way in which the body is represented (see feature 1). The structure of the body has undergone a major change since a limb has been amputated, but the dot still represents the source of the pain where it would have been if the limb were still there. Since the structure of the body has changed, the representation of the position of the dot is physically misplaced. The problem is to be ascribed to a feature of our representational system, that of representing the body according to the body schema and not updating all changes to the actual bodily state.

There is empirical evidence in this sense: the body map represents the body in its integrity even if the subject is born without a limb or has undergone amputation in early infancy. (Melzack et al 1987; Montoya et al. 1998). This is a case of first order representational pain. Indeed, Ramachandran and colleagues (1996; 1998, Ramachandran and Hirstein 1998) have devised treatments for phantom pain based on this principle: patients are helped by means of a mirror which substitutes an image of their existing for their amputated limb. This can be considered a representational treatment for a representational pain.

The second case to consider is chronic pain. ${ }^{20}$ Chronic pain is the remnant of an acute pain and a behavioral attitude towards that pain which leads to a defensive behavior which in turn, ultimately, fixes an (at least) partially imaginary pain. Chronic pain thus stems from a different malfunction of the representational system: the system retains a trace of the position of the original painful location in a format that differs from that of the original pain. The analogy here is with the worn away dot, whose position has to be inferred from the physical traces on the map : $_{s}$ as visitors repeatedly touch the dot, it may disappear from the map, but its original position can be inferred by the very evidence that this point has been fre-

\footnotetext{
${ }^{19}$ For an interpretation of the content of pain experiences as commands on what to do see Klein (2015).

${ }^{20}$ Phantom limb can be considered as a special case of chronic pain. However, the model I am suggesting may treat it differently. Hardcastle argues that there is no solid evidence that chronic pain lacks a physical cause. According to her: "It looks as though all pains are created equal, after all". Hardcastle (1999: 21)
} 
quently touched. The map represents the position that the representation of pain used to have, not the position of pain itself: it represents where the representation of pain used to be. So, it is a second order representational pain. As with the map ${ }_{s}$, the presence of pain is inferred from a map that does not "refresh itself", so to say, but somehow records its prior use. So, our representational system overinterprets the signal it receives according to its original value (there is a pain here) rather than its actual value (there was a pain here).

The third case is referred pain, in which the physical origin and the phenomenal location of pain differ. First, we should notice that using referred pain as a case against representationalism is somehow misleading. In calling pain "referred", one is implicitly suggesting that there is both a real and an apparent location. Now, if the physical origin of pain ${ }^{21}$ is taken as the proper location of some non-referred pain, this would entail accepting the idea that the cause is a bona fide location of pain. But this would assume a stronger thesis than that proposed by representationalism, that is the view offered by perceptualism that sensations are to be identified with their physical locations. Representationalism is not necessarily committed to this stronger thesis, but rather to the thesis that pain represents the location of its origin. Notwithstanding this argument, we may nevertheless consider the case in which the represented location does not target the physical origin of pain but some other spot. In terms of our metaphor, the body is correctly represented but the point where the pain occurs is not.

On the cause of referred pain, some suggest that this occurs when nerves from different anatomic areas or sites converge on the same neuronal pathway in the spinal cord. When the pain signal reaches the brain, signals coming from these different sites may be conflated, resulting in perceived pain from one part of the body being referred to another. Hence, pathways for the various form of referred pain have been proposed (Simmons 1998). But these are not uniformly accepted: “... although pain from different segments in the lumbar spine refers to different regions in the lower limb, patterns are not consistent amongst subjects or between studies. [...] If anything, the pattern corresponds to the segmental innervation of deep tissues in the lower limb, such as muscles and joints." (Bogduk 2009: 17) So, empirical scientists are still working to establish a unitary model, if one can be found.

In the light of the map analogy and the model proposed, we can read this situation as one in which, given the po-

\footnotetext{
${ }^{21}$ Like a nerve pinched or a heart fibrillating, where these are the proper physical origins of the painful end of the pinched nerve or the painful left arm.
} 


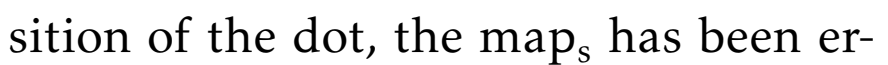
roneously located. As a consequence, the dot indicates the wrong place to the reader, who obviously assumes that "you are here" refers to herself and that the map is correctly located. Consequently, she acts erroneously, that is, she goes in the wrong direction because of the mistaken information she has acquired. Alternatively, we can imagine that there must be some limits on fine tuning the map with respect to forking paths: the representational system may not be precise or accurate enough to distinguish paths that cross each other.

Now, it is an empirically open question whether this is what really happens with our body, if this is the way in which our body map actually works and so forth. But, from an abstract point of view, the model makes it clear that it is not necessarily a consequence of the $\mathrm{P} / \mathrm{R}$ theory projecting the pain to the wrong or incorrect position. Instead, it amounts to the representational system suffering from some kind of structural shortcoming or maladaptation, which then results in referred pain. In sum, the inadequacy should be ascribed to the representational system, to our physical and cognitive machinery, not to the representational theory. That such inadequacies exist is not in itself surprising. As we have already seen, if the structure where the map is to be placed were symmetrical, then some potential dot positions would be intrinsically ambiguous and could not be sorted out by any specific repositioning of the map. The cases we have considered, a pinched nerve or heart attack, are not of the symmetrical kind, but show that the representational system does not always provide adequate information for tracing where physical damage, either actual or potential, occurs. 22

Summing up, in all three cases, it is perfectly clear why these incongruities occur: they are due to failures of the representational system, and do not require us to postulate a logical difference between pain and perceptual reports. The way in which the information from the body is conveyed to our consciousness via the representational system, thus comes to form the content of our experiential states, makes it clear that there are structural limits to the representational system, rather than the representational theory.

Sabrina Coninx (2020) has advanced a general objection to the representationalist model in a recent paper.23 According to her, representationalism is based on the idea that pain sensati-

\footnotetext{
${ }^{22}$ For a philosophical assessment of [the importance of] our body map and body schema (and their differences) and the importance of visual perception in bodily awareness, see de Vignemont $(2010,2014)$.

${ }^{23}$ Aydede (2019) has launched another attack on representationalism, by criticizing what he calls the "transparency thesis": according to him, representationalism assumes a strong form of the transparency thesis, which runs counter to some empirical evidence. Hence, representationalism is false under such an assumption. I do not have space here to discuss this new challenge.
} 
ons causally covariate with a uniform class of causes and biological functions. However, since neither causes nor functions are uniform, but instead actually different in kind, the foundations of representationalism are shaky. Most of Coninx's paper is devoted to the issue of the intensity of pain and its possible effects in terms of damage, so it is tangentially related to the issue of location. Hill (2012), Coninx notes, offers an interesting potential defense: the content of our representation is not that one is in pain, but that the stimuli is subjectively taken to be an actual or potential harm or impairment to the biological functions of the individual. So, harm depends on many other factors, and causal covariance is much more articulated, as Coninx herself argues. As a rejoinder to Hill's strategy, Coninx writes:

Following the outlined approach, considerations concerning reliable causal covariance and biological function show that the intentional contents of multiple bodily sensations collapse in the representation of actual or potential harm. Phenomenal differences between pain, hunger, and itches thus cannot be explained in terms of their intentional content. This conclusion contradicts the main assumption of strong representationalism that every difference in phenomenology relies on a corresponding difference in intentionality (Coninx 2020:14)

It is far from clear how this conclusion can be drawn. The fact that, say, pain and itches are actual or potential harms does not prevent them from being phenomenally different kinds of harm. For, representationalism still retains the possibility of qualifying such representational content simply by specifying the way in which the subject is stimulated. So, if the content of representations is given by phenomenal goings-on, then surely different goingson determine different representational contents. To wit: harm to my left or right hand is categorized as harm, but in the first case draws my attention to my left hand, while in the second case to my right hand.

How does the interactionist and externalist second person view promoted by Davidson relate to this issue? The nature of a representation is that of conveying information that points beyond the representational system itself. Like intentional states, representations are outward reaching states, pointing to some state of affairs. They are not a way to implement just a self-check on behalf of the representational system. The body map represents the body and its condition. In learning the concept of pain, we learn how to coordinate the information received from this representational system with representations of our own and other bodies, such as a second person. 


\section{Acknowledgements}

\section{For comments and suggestions on a previous draft, I express my gratitude to Cristina Amoretti, Ivan Cotumaccio, and Donatella Donati.}

\section{References}

AMORETTI, C. (2012) "Sul carattere sociale di pensiero e linguaggio", RIFL. Rivista Italiana di Filosofia del Linguaggio: 4-16.

AMORETTI, C. (2013) “Concepts within the Model of Triangulation”, Protosociology 30: 50-63.

ARENDT-NIELSEN et al. (2001) "Referred Muscle Pain: Basic and Clinical Findings", The Clinical Journal of Pain: March 2001, 17(1): 11-19.

ARMSTRONG, D. M. (1968). A Materialist Theory of the Mind. New York: Humanities Press.

ARMSTRONG, D. M; MALCOLM, N. (1984). Consciousness and Causality. Oxford: Blackwell.

AYDEDE, M. (2005). "A Critical and Quasi-Historical Essay on Theories of Pain.” In AYDEDE, M. (Ed.), Pain: New Essays on Its Nature and the Methodology of Its Study. Cambridge MA: MIT Press, pp. 1-58.

AYDEDE, M. (2009). "Is Feeling Pain the Perception of Something?” Journal of Philosophy, 106, pp. 531-67.

AYDEDE, M. (2013). "Pain". The Stanford Encyclopedia of Philosophy (Spring 2013 Edition), ZALTA, Edward N. (ed.), $\mathrm{URL}=$ http://plato.stanford.edu/archives/spr2013/entries/pain/

AYDEDE, M. (2017). "Pain: Perception or Introspection?". In J. CORNS (Ed.), The Routledge Handbook of Philosophy of Pain. Abingdon: Routledge, pp. 221-231.

AYDEDE, M. (2019) "Is the Experience of Pain Transparent?", Synthese, 196: 677-708.

AYDEDE, M. (2020) "What is a Pain in a Body Part?", The Canadian Journal of Philosophy, 50: 143- 158.

BAIN, D. (2003). "Intentionalism and Pain.” Philosophical Quarterly, 53, pp. 502-23.

BAIN, D. (2007). "The Location of Pains." Philosophical Papers, 36 (2), pp. 171-205.

BAIN, D. (2013). “What Makes Pains Unpleasant?” Philosophical Studies, 166, pp. S69-S89.

BOGDUK, N. (2009) "On the definitions and physiology of back pain, referred pain, and radicular pain", Pain 147: 17-29.

BROGAARD, B. (2011). "Perceptual Reports." In M. MATTHEN (Ed) Oxford Handbook of the Philosophy of Perception, Oxford: Oxford University Press, pp. 237-255.

BROGAARD, B. (2012). “What do We Say When We Say How or What We Feel?” Philosophers' Imprint, 12 (11), pp. 1-22. CLARK, A. (2000) A Theory of Sentience, Cambridge, Cambridge University Press.

CONINX, S. (2020) "Strong representationalism and bodily sensations: Reliable causal covariance and biological function", Philosophical Psychology. 34:2, 210-232.

CORNS, J. (2017) (Ed). The Routledge Handbook of Philosophy of Pain. Abingdon: Routledge.

CUTTER, B. (2017). "Pain and Representation." In CORNS, J. (Ed) The Routledge Handbook of Philosophy of Pain, Abingdon: Routledge, pp. 29-39.

CUTTER, B.; TYE, M. (2011). “Tracking Representationalism and the Painfulness of Pain.” Philosophical Issues, 21, pp. 90-109.

DAVIDSON, D. (1992) "The Second Person”, now in DAVIDSON, D. (Ed) Subjective, Intersubjective, Objective, Oxford: Oxford University Press: 107-22.

DAVIDSON, D. (1997) “The Emergence of Thought", now in DAVIDSON, D. (Ed) Subjective, Intersubjective, Objective, Oxford: Oxford University Press: 123-134.

DAVIDSON, D. (1998a) "Interpretation: Hard in Theory, Easy in Practice", in PRAWITZ, D. (ed.) Meaning and Interpretation, Stockholm: Kungliga Vitterhets Historie och Antikvitets Akademien: 71- 86.

DAVIDSON, D. (1988b) “The myth of the subjective" in DAVIDSON, D. (Ed) Subjective, Intersubjective, Objective, Oxford University Press, Oxford: 39-52.

DAVIDSON, D. (2001) “Introduction” in DAVIDSON, D. (Ed) Subjective, Intersubjective, Objective, Oxford University Press, Oxford.

DEAMER, F. (2021) “Why Do We Talk to Ourselves?”, Review of Philosophy and Psychology, 12, pages 425-433. 
DRETSKE, F. (2006). “The Epistemology of Pain.” In AYDEDE, M. (Ed) Pain: New Essays on its Nature and the Methodology of Its Study. Cambridge MA: MIT Press, pp. 59-74.

GOZZANO, S. (1997) Intenzionalità, contenuto e comportamento, Armando, Roma.

GOZZANO, S. (2019) “Locating and Representing Pain”, Philosophical Investigation, 42: 313-332.

HARDCASTLE, V.G. (1999). The Myth of Pain. Cambridge MA: MIT Press.

HILL, C. (2004). "Ouch! An Essay on Pain” in R. GENNARO (Ed) Higher-Order Theories of Consciousness: An Anthology, Amsterdam: Benjamins, pp. 339-62.

HILL, C. (2006). "Ow! The Paradox of Pain”, in AYDEDE, M. (Ed) Pain: New Essays on its Nature and the Methodology of Its Study. Cambridge MA: MIT Press, pp. 75-98.

HILL, C. S. (2012). "Locating qualia: Do they reside in the brain or in the body and the world?" In GOZZANO, S. HILL, C. S. (Eds.), New perspectives on type identity: The mental and the physical, Cambridge University Press: $127-149$.

HILL, C. (2017). "Fault lines in familiar concepts of pain" in J. CORNS (Ed), The Routledge Handbook of Philosophy of Pain, Abingdon: Routledge, pp. 60-70.

IASP - International Association for the Study of Pain (1986). "Pain Terms: A List with Definitions and Notes on Pain." Pain, 3 (Suppl.), pp. 216-21.

KLEIN, C. (2015). What the Body Commands, Cambridge, Mass.: MIT Press.

KRIPKE, S. (1989) “A puzzle about belief”, in MARGALIT, A. (ed.) Meaning and Use, Reidel, Dordrecht: $239-283$.

KRIPKE, S. (1980) Naming and Necessity, Harvard University Press.

MELZACK, R. (1997) "Phantom limbs in people with congenital limb deficiency or amputation in early childhood", Brain 120 (Pt 9): 1603-20.

MONTOYA, P. et al. (1998) "The cortical somatotopic map and phantom phenomena in subjects with congenital limb atrophy and traumatic amputees with phantom limb pain", European Journal of Neuroscience, 10(3): 1095-102.

PITCHER, G. (1970). "Pain Perception." Philosophical Review, 79: 368-93.

RAJA, S. et al. (2020) "The revised International Association for the Study of Pain definition of pain: concepts, challenges, and compromises", PAIN, 161 (9): 1976-1982.

RAMACHANDRAN, V.S. and ROGERS-RAMACHANDRAN, D. (1996). "Synaesthesia in phantom limbs induced with mirrors." Proceedings of the Royal Society of London, 263: 377-386.

RAMACHANDRAN, V.S. (1998). "Consciousness and body image: Lessons from phantom limbs, Capgras syndrome and pain asymbolia." Philosophical Transaction of the Royal Society B: Biological Sciences, 353, pp. 1851-9.

RAMACHANDRAN, V.S. and HIRSTEIN, W. (1998). “The Perception of Phantom Limbs”, Brain 12: $1603-30$.

REUTERS, K. PHILIPS, D. and SYTSMA J. (2013). "Hallucinating Pain" in J. SYTSMA (Ed.) Advances in Experimental Philosophy of Mind, London: Bloomsbury Press: 75-100.

REUTERS, K. and SYTSMA J. (2020) "Unfelt pain”, Synthese, 197: 1777-1801

SIMMONS, D.G. (1998) In SIMMONS, DG; TRAVELL, JG;SIMONS, L; eds. Myofascial pain and dysfunction. The trigger point manual. Baltimore: Williams Wilkins 2: 1-10.

TYE, M. (1995). “A Representational Theory of Pains and their Phenomenal Character." Philosophical Perspectives 9: 223-239.

TYE, M. (2006a). “Another Look at Representationalism about Pain” in AYDEDE, M. (Ed.) Pain: New Essays on Its Nature and the Methodology of Its Study. Cambridge MA: MIT Press: 99-120.

TYE, M. (2006b). "In Defense of Representationalism: Reply to Commentaries." In AYDEDE, M. (Ed.) Pain: New Essays on Its Nature and the Methodology of Its Study. Cambridge MA: MIT Press: 163- 176.

TYE, M. (2014). "What is the Content of a Hallucinatory Experience?" In BROGAARD, B. (Ed.) Does Perception Have Content? Oxford: Oxford University Press: 291-309.

TYE, M. (2016). "The Nature of Pain and the Appearance/Reality Distinction" in COATES, P. et al. (Eds.) Phenomenal Qualities: Sense, Perception and Consciousness, Oxford: Oxford University Press: 298-321.

TYE, M. (2017). “Are pains feelings?” The Monist, 100: 478-484.

VERHEGGEN (2007) “Triangulating with Davidson”, The Philosophical Quarterly, 57: 96-103.

de VIGNEMONT, F. (2010). “Body schema and body image: pros and cons”. Neuropsychologia, 48(3): 669-80.

de VIGNEMONT, F. (2014). “A Multimodal Conception of Bodily Experience.” Mind 123: 989-1020.

Received: $02 / 02 / 2021$

Approved: $12 / 03 / 2021$

Published: $30 / 04 / 2021$ 